\title{
AVALIAÇÃO DE TOXICIDADE APÓS SUBMISSÃO DE EFLUENTE ORIUNDO DE ETE AO PROCESSO FOTO-FENTON LIKE FRENTE À SEMENTE DE Lactuta Sativa E AO GRÃO Americano Hard.
}

\author{
D. C. NAPOLEÃO ${ }^{1}$, R. B. PINHEIRO ${ }^{1}$, L. E. M. C. ZAIDAN ${ }^{1}$, R. V. L. SALES ${ }^{1}$, M. \\ BENACHOUR $^{1}$ e V. L. SILVA ${ }^{1}$ \\ ${ }^{1}$ Universidade Federal de Pernambuco, Departamento de Engenharia Química \\ E-mail para contato: danicarlan@gmail.com
}

\begin{abstract}
RESUMO - Os Processos Oxidativos Avançados (POA), como o Foto-Fenton Like, têm sido empregados para promover a degradação de compostos persistentes em matrizes aquosas após submissão aos processos convencionais de tratamento de efluentes. Entretanto, surge uma preocupação em torno dos compostos formados após submissão ao POA, sendo necessário dispor técnicas rápidas e práticas para avaliar a toxidade das águas. Ensaios toxicológicos com sementes e grãos avaliam a germinação e o crescimento quando irrigados com efluentes submetidos aos tratamentos não convencionais. Este trabalho avaliou a toxicidade de efluente oriundo de ETE farmacêutica após submissão a POA frente à semente de Lactuta sativa e ao grão Americano Hard. Os ensaios, realizados em triplicata, demonstraram que as diferentes concentrações de efluentes não interferiram na germinação das espécies, mas que retardaram o crescimento radicular do grão em concentrações superiores a $50 \%$ do efluente.
\end{abstract}

\section{INTRODUÇÃO}

Os tratamentos convencionais de tratamento de efluentes (físico-químico e biológico) na maioria das vezes não conseguem promover a degradação de determinadas substâncias, fazendo com que essas sejam encontradas nas matrizes ambientais em concentrações dos mais diferentes níveis. Promover a degradação destes compostos é, portanto, imprescindível, tendo em vista que a maioria deles causam danos à saúde de seres humanos e animais, além de serem recalcitrantes e refratários. É o caso de produtos farmacêuticos e de uso de higiene pessoal, assim como de hormônios e plastificantes (Schwarzenbach, et al., 2006; HINZ, et al., 2007).

Poluentes como fármacos, hormônios, plastificantes, hidrocarbonetos policíclicos aromáticos (HPA) quando acumulados podem alterar o sistema endócrino dos seres vivos, que atua de uma forma complexa, atuando no crescimento e no metabolismo do organismo. Quando essas substâncias são lançadas nas matrizes aquosas contaminam o meio ambiente, pois apesar de apresentam um tempo de 


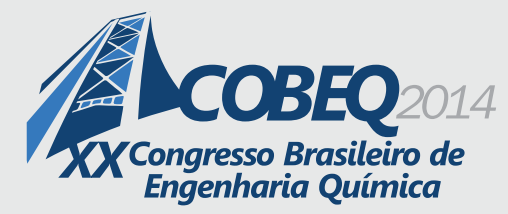

meia vida razoável é persistente e alteram o ecossistema em que se depositam (REIS FILHO et al., 2006).

Diversos métodos são empregados com o objetivo de promover a eliminação de compostos orgânicos não biodegradáveis, sendo os Processos Oxidativos Avançados (POA) largamente difundidos em todo mundo. Os POA são tratamentos alternativos que através da geração do radical hidroxila conseguem reagir com grande parte de substâncias orgânicas levando a mineralização destes e formando como produtos dióxido de carbono e água (ZAFRA-GÓMEZ et al., 2008).

Dentre os POA, o processo Foto-Fenton apresenta como principal vantagem uma maior sensibilidade à luz em comprimentos de onda de até $600 \mathrm{~nm}$, o que corresponde a $35 \%$ da irradiação solar (MALATO et al., 2002). Este processo consegue promover redução de custos, pois é possível substituir a luz artificial pela luz solar, energia de baixo custo dependendo da localização, como ocorre no Nordeste Brasileiro.

A avaliação da eficiência do tratamento via POA é comumente realizada empregando métodos analíticos como a extração em fase sólida (EFS) e técnicas cromatográficas, como a cromatografia líquida de alta eficiência (CLAE). A EFS é empregada como etapa de pré-tratamento da amostra, enquanto que a CLAE é utilizada na determinação e quantificação dos compostos de interesse (NAPOLEÃO, 2011).

Uma preocupação recente em torno do emprego de diferentes tipos de POA consiste na formação de intermediários, os quais são formados durante o tratamento. Desse modo, é realizar estudos de toxicidade que sejam capazes de avaliar a toxicidade dos efluentes submetidos a tratamentos alternativo, tendo em vista seu posterior lançamento em corpos receptores, que precisam ter assegurado o seu equilíbrio sem causar danos ao meio ambiente (MELO et al., 2009).

\subsection{Toxicidade de Matrizes Aquáticas}

Os testes de toxicidade são ensaios realizados sobre determinadas condições laboratoriais para verificar a toxicidade dos compostos em estudos em efluentes industriais e diferentes tipos de amostras ambientais. Os testes de toxicidade podem ser classificados de acordo com o tempo de exposição (crônico ou agudo), ou ainda com relação ao efeito: modo de efeito (morte, crescimento ou germinação/reprodução) e resposta do efeito (sub-letal ou letal). Com relação ao estudo da toxicidade de efluentes é comum observar teste de modo de efeito avaliando o crescimento e ainda a letalidade da substância frente a sementes e a letalidade (KAPANEN; ITAVAARA, 2001).

A germinação de sementes é um método rápido e prático empregado para analisar a toxicidade de efluentes tratados. Verifica-se que quando sementes são embebidas com água há uma hidratação dos tecidos, levando a um aumento da respiração o que resulta em um maior crescimento dos embriões (NASSIF et al., 1998 apud BRITO-PELEGRINI, et al. 20??.)

A vantagem em se trabalhar com sementes para avaliar se determinada substância é tóxica ou não está no fato de que os ensaios são extremamente simples e não necessitam da utilização de 


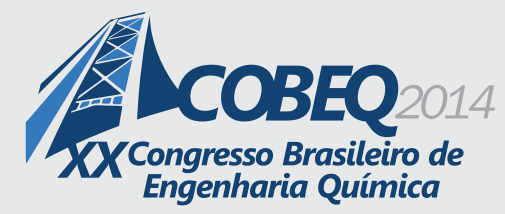

equipamentos sofisticados para realização dos experimentos.

O presente trabalho tem como objetivo avaliar a toxicidade de um efluente farmacêutico submetido ao POA Foto-Fenton Like frente à semente de Lactuta Sativa e ao grão Americano Hard.

\section{METODOLOGIA}

\subsection{Tratamento do Efluente: Emprego do Processo Foto-Fenton Like}

Primeiramente foi realizado um estudo prévio para caracterização do efluente segundo os padrões de qualidade exigidos pelo CONAMA 430 (BRASIL, 2011). O efluente analisado foi oriundo de ETE de indústria farmacêutica do estado de Pernambuco, tendo sido realizada a coleta no dia 05 de março de 2013.

Os materiais e vidrarias utilizados na coleta das amostras serão lavados com água, detergente e água deionizada. Após a lavagem, os mesmos foram colocados em mufla a $400^{\circ} \mathrm{C}$ para que possam ser eliminados possíveis resíduos orgânicos. As vidrarias volumétricas foram deixadas em solução aquosa contendo Extran $2 \%$ (neutro) durante $24 \mathrm{~h}$, em seguida foram colocadas em solução de ácido nítrico a $15 \%$ também por um período de $24 \mathrm{~h}$. Por fim, o efluente coletado foi armazenado em geladeira a uma temperatura de $22 \pm 2^{\circ} \mathrm{C}$.

O efluente foi submetido ao POA Foto-Fenton Like em reator de bancada com 3 lâmpadas UV$\mathrm{C}$ (Philips, 30W, cada uma). Em um recipiente de vidro foram colocados $500 \mathrm{~mL}$ do efluente, com uma altura do efluente igual a 2,0 $\pm 0,1 \mathrm{~cm}$. Em seguida, foram adicionados $5 \mathrm{~mL}$ de $\mathrm{H}_{2} \mathrm{O}_{2}(\mathrm{~F}$. Maia) nos tempos 0, 30, 60 e 90 minutos. O tempo total de submissão do efluente a radiação foi igual a 120 minutos. É importante ressaltar que não foi necessário acrescentar ferro (Processo Foto-Fenton Like), pois o mesmo encontrava-se presente na amostra analisada com concentração igual a $0,64 \mathrm{mg} . \mathrm{L}^{-1}$.

A determinação da presença/ausência de 4 fármacos (ácido acetilsalicílico - AAS, diclofenaco, dipirona e paracetamol) foi realizada em equipamento de CLAE (Shimadzu) com método previamente validado. O equipamento utilizado foi equipado com a coluna ULTRA C18 de fase reversa $(5 \mu \mathrm{m} ; 4,6 \mathrm{x}$ $250 \mathrm{~mm}$ ) e detecção UV (SPD-20A) para comprimentos de onda iguais a $285 \mathrm{~nm}$. A fase móvel empregada foi composta por uma solução de água acidificada com ácido acético a $10 \%$ e acetonitrila numa razão de 65:35. A temperatura do forno do equipamento foi mantida a $40 \pm 1^{\circ} \mathrm{C}$ com o fluxo de $0,700 \mathrm{~mL} \cdot \mathrm{min}^{-1}$ e a uma pressão de $53 \mathrm{kgf} . \mathrm{C}^{-1}$. Os compostos analisados foram observados em tempos de retenção característicos sendo: AAS (4,0 - 4,2 min), Diclofenaco (8,4 - 8,7 min), Dipirona (2,8 3,0 min) e Paracetamol (3,5 - 3,8 min).

Tendo em vista o fato da metodologia empregada, utilizar como fase móvel acetonitrila/metanol, fez-se necessário empregar uma etapa de pré-tratamento da amostra, já que se encontrava na forma aquosa. A extração sólido-líquido foi realizada utilizando cartuchos poliméricos strata-X operando em fase reversa $(500 \mathrm{mg} / 6 \mathrm{~mL}$ - Allcrom). Esse tipo de cartucho é capaz de reter fortemente compostos neutros, ácidos e básicos utilizando solventes orgânicos. Para tal procedimento foi utilizada bomba peristáltica (Wilson) operando a uma vazão igual a $10 \mathrm{~mL} \cdot \mathrm{min}^{-1}$; a fase 


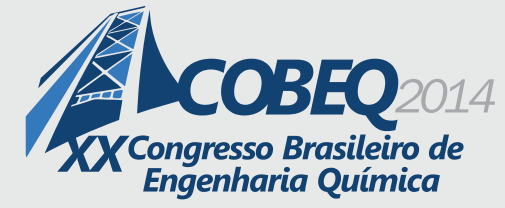

19 a 22 de outubro de 2014

Florianópolis/SC

estacionária foi condicionada com duas alíquotas de $3 \mathrm{~mL}$ de acetonitrila (Merck), sendo em seguida adicionadas duas alíquotas de $3 \mathrm{~mL}$ de água ultra-pura. Uma vez condicionados os cartuchos foram filtrados os efluentes em estudo. O volume de amostra utilizado para análise foi igual a $500 \mathrm{~mL}$.

\subsection{Estudo da Toxicidade}

O método para avaliação da toxicidade consiste na exposição de sementes e dos grãos por um período de 120 horas para a semente de Lactuta Sativa e por 72 horas para o grão Americano Hard, a diferentes concentrações do efluente líquido, sem renovação das soluções. Para os bioensaios com foram utilizadas placas de Petri e papel filtro como meio suporte. Foram realizados ensaios em concentrações iguais a $100 \% ; 70 \% ; 50 \% ; 10 \% ; 5 \%$ e $1 \%$ do efluente. Sobre o papel filtro foram colocadas 10 sementes/grãos e $2 \mathrm{~mL}$ da solução-teste em cada placa. As análises foram feitas em triplicatas para cada concentração da solução-teste.

A água foi utilizada como controle negativo, e o Boro, na forma de uma solução de ácido bórico, como controle positivo, no teste de sensibilidade. $\mathrm{O}$ volume utilizado de cada um foi igual ao volume do efluente em estudo $(2 \mathrm{~mL})$. As placas de Petri contendo os ensaios para a realização dos testes de toxicidade foram mantidas à temperatura de $25 \pm 1{ }^{\circ} \mathrm{C}$, em ausência de luz. Foram observados os números de sementes que germinaram em cada concentração do efluente utilizado, bem como nos controles positivo e negativo.

\section{RESULTADOS}

\subsection{Tratamento do Efluente: Emprego do Processo Foto-Fenton Like}

Inicialmente, foi realizada a caracterização do efluente, cujos valores dos principais parâmetros físico-químicos estão dispostos na Tabela 1. É importante observar que todos os valores estão em concordância com os padrões exigidos pelo CONAMA 430 (BRASIL, 2011), o que garante a eficácia do tratamento convencional no que diz respeito às análises de qualidade.

Com base nos resultados da Tabela 1 e verificado que o tratamento da ETE foi eficiente para as exigências do CONAMA, passou a fase de detecção e quantificação dos fármacos em estudo. 
Tabela 1 - Resultados análises dos parâmetros de qualidade do efluente.

\begin{tabular}{|c|c|c|}
\hline Análise & Efluente & $\begin{array}{c}\text { CONAMA } \\
430 / 2011 \\
\end{array}$ \\
\hline DQO (mg.L $\mathrm{L}^{-1} \mathrm{de} \mathrm{O}_{2}$ ) & 396,10 & - \\
\hline $\mathrm{DBO}\left(\mathrm{mg} . \mathrm{L}^{-1}\right.$ de $\left.\mathrm{O}_{2}\right)$ & 174,50 & $<5$ \\
\hline ST $\left(m g . L^{-1}\right)$ & 227,80 & $<500$ \\
\hline STV (mg.L $\left.{ }^{-1}\right)$ & 71,17 & - \\
\hline STF (mg. $\left.\mathrm{L}^{-1}\right)$ & 119,00 & - \\
\hline $\mathrm{pH}$ & 5,86 & $5 \leq \mathrm{pH} \leq 9$ \\
\hline Ferro $\left(\mathrm{mg} . \mathrm{L}^{-1} \mathrm{Fe}\right)$ & 0,63 & $<15,0$ \\
\hline Cromo $\left(\mathrm{mg} . \mathrm{L}^{-1} \mathrm{Cr}\right)$ & $<0,13$ & $<1,1$ \\
\hline Chumbo (mg.L $\left.\mathrm{L}^{-1} \mathrm{~Pb}\right)$ & $<0,16$ & $<0,5$ \\
\hline Níquel (mg.L $\left.\mathrm{L}^{-1} \mathrm{Ni}\right)$ & $<0,11$ & $<2,0$ \\
\hline Zinco (mg.L $\left.\mathrm{L}^{-1} \mathrm{Zi}\right)$ & $<0,005$ & $<5,0$ \\
\hline Cádmio (mg.L $\left.\mathrm{L}^{-1} \mathrm{Cd}\right)$ & $<0,2$ & $<0,2$ \\
\hline $\begin{array}{c}\text { Manganês } \\
\left(\mathrm{mg} \cdot \mathrm{L}^{-1} \mathrm{Mn}\right)\end{array}$ & $<0,05$ & $<1,0$ \\
\hline Cobre $\left(\mathrm{mg} . \mathrm{L}^{-1} \mathrm{Cu}\right)$ & 0,01 & $<1,0$ \\
\hline
\end{tabular}

Foram detectados 3 dos 4 fármacos analisados no efluente oriundo de ETE de indústria farmacêutica nas seguintes concentrações: AAS $\left(0,65 \mathrm{mg} . \mathrm{L}^{-1}\right)$, Dipirona $\left(3,92 \mathrm{mg} . \mathrm{L}^{-1}\right)$ e Paracetamol $\left(1,57 \mathrm{mg} . \mathrm{L}^{-1}\right)$. Sendo assim foi necessário propor tratamento para esta matriz ambiental de modo a degradar as drogas encontradas. Para tal os Processos Oxidativos Avançados (POA) tem sido amplamente utilizados, conseguindo degradar esses poluentes.

O tratamento aplicado para degradação dos fármacos mostrou-se eficiente, tendo em vista que apenas dois dos três fármacos foram detectados após o processo. Os compostos AAS e paracetamol não foram observados após submissão a análise cromatográfica, no entanto o fármaco dipirona foi ainda observado. Uma vez quantificada a concentração de dipirona, foi possível determinar o percentual de degradação desse composto, sendo, igual a 97,81\%. Pode-se afirmar ainda que aproximadamente $100 \%$ do AAS e do paracetamol foram detectados, já que o método para detecção e quantificação desses compostos foi previamente validado.

\subsection{Estudo da Toxicidade}

Tendo sido observada a eficiência do tratamento empregado pôde-se avaliar a toxicidade das substâncias que são formadas após submissão ao POA frente à semente de Lactuta Sativa e do grão Americano Hard. A Tabela 2 apresenta os resultados obtidos para a germinação de cada espécie estudada. 


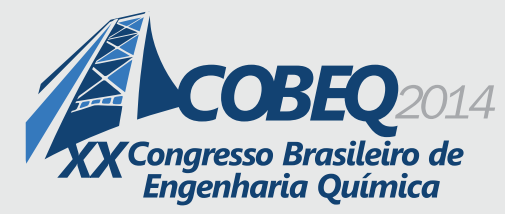

19 a 22 de outubro de 2014

Florianópolis/SC

Tabela 2 - Quantidade de sementes /grão germinados para cada espécie estudada (ensaios em triplicata).

\begin{tabular}{|c|c|c|}
\hline Efluente / Solução-teste & Lactuta Sativa & Americano Hard \\
\hline Água & $7 ; 6 ; 5$ & $10 ; 9 ; 10$ \\
\hline Ácido Bórico & $0 ; 0 ; 0$ & $0 ; 0 ; 0$ \\
\hline $1 \%$ de efluente & $4 ; 7 ; 4$ & $10 ; 10 ; 10$ \\
\hline $5 \%$ de efluente & $4 ; 6 ; 4$ & $10 ; 10 ; 10$ \\
\hline $10 \%$ de efluente & $5 ; 3 ; 5$ & $10 ; 10 ; 10$ \\
\hline $50 \%$ de efluente & $5 ; 3 ; 6$ & $10 ; 10 ; 10$ \\
\hline $70 \%$ de efluente & $5 ; 6 ; 5$ & $10 ; 9 ; 10$ \\
\hline $100 \%$ de efluente & $4 ; 4 ; 3$ & $9 ; 10 ; 10$ \\
\hline Efluente sem tratamento & $6 ; 3 ; 3$ & $10 ; 9 ; 10$ \\
\hline
\end{tabular}

A análise da Tabela 2 mostra que para o grão trigo da espécie Americano Hard o efluente comportou-se da mesma forma que o controle negativo para as diferentes concentrações avaliadas, de modo que se pode afirmar que os compostos formados após o tratamento aplicado não apresentam toxicidade para o grão. Com relação à semente de alface da espécie de Lactuta Sativa verificou-se uma maior variação na quantidade de sementes germinadas, inclusive para o controle negativo. É importante ressaltar, que para este tipo de semente é necessário realizar a quebra de dormência da mesma para que os resultados possam ser mais confiáveis, o que não foi efetuado no presente trabalho (LOPES; NASCIMENTO, 2012). Entretanto, pode-se afirmar que não houve grandes interferências na germinação das sementes nas diferentes concentrações de efluentes estudadas, podendo-se afirmar assim como feito para o grão de trigo que os compostos formados pós-tratamento não apresentam toxicidade para este tipo de semente no que diz respeito à análise de germinação.

Uma vez avaliada a germinação, passou-se a observar o crescimento da radícula, neste caso optou-se por avaliar apenas o grão Americano Hard, tendo em vista a apresentação de uma maior germinação no estudo anterior. Vale ressaltar que foram medidas as raízes que apresentaram maior comprimento para cada uma das Placas de Petri analisadas. A Tabela 3 mostra os resultados do crescimento radicular.

Tabela 3 - Crescimento radicular do grão Americano Hard (ensaios em triplicata).

\begin{tabular}{|c|c|}
\hline Efluente / Solução-teste & Comprimento da raiz (cm) \\
\hline Água & 4,$0 ; 3,0 ; 2,6$ \\
\hline $1 \%$ de efluente & 3,$8 ; 2,1 ; 1,9$ \\
\hline $5 \%$ de efluente & 3,$1 ; 1,8 ; 1,4$ \\
\hline $10 \%$ de efluente & 1,$6 ; 1,3 ; 1,6$ \\
\hline $50 \%$ de efluente & 1,$0 ; 1,5 ; 0,9$ \\
\hline $70 \%$ de efluente & 0,$5 ; 0,9 ; 1,1$ \\
\hline $100 \%$ de efluente & 0,$7 ; 0,9 ; 1,1$ \\
\hline
\end{tabular}




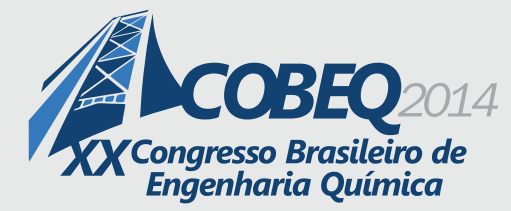

A análise da Tabela 3 mostra que para as concentrações mais altas do efluente houve uma inibição do crescimento das raízes, demonstrando que apesar dos compostos formados após aplicação do POA não interferirem na germinação, causam alguns danos no desenvolvimento do grão estudado. Entretanto, sabe-se que os efluentes ao serem lançados nos corpos receptores sofrem diluição, assemelhando-se as condições dos ensaios com concentrações de efluentes inferiores a 50\%, não causando assim grandes alterações no crescimento das espécies.

É importante, dessa forma, realizar maiores estudos sobre a toxicidade, empregando outras sementes para que se possam ter resultados mais completos. De toda forma, os estudos mostram a importância de se verificar além da eficácia do tratamento via POA, a toxicidade dos compostos formados após as reações, sendo a análise desses produtos de extrema importância para que não sejam gerados compostos mais tóxicos que os iniciais, causando danos mais severos ao ambiente.

\section{CONCLUSÃO}

A análise do efluente em estudo demonstrou a presença de três fármacos em concentrações relativamente altas (dipirona, AAS e paracetamol). O emprego do processo Foto-Fenton Like utilizado em Efluente oriundo de ETE farmacêutico mostrou-se eficaz na degradação dos fármacos estudados, conseguindo obter $100 \%$ de degradação. O estudo da toxicidade do efluente após submissão ao POA mostrou não haver interferência na germinação da Lactuta Sativa, bem como do Americano Hard. Entretanto, o estudo do crescimento radicular da segunda espécie demonstrou que para concentrações mais altas do efluente (acima de 50\%) há uma interferência no crescimento, sendo imprescindível a diluição do efluente nos corpos receptores.

\section{REFERENCIAS}

BRASIL. Ministério do Meio Ambiente. Resolução nº 430, de 13 de maio de 2011. Conselho Nacional do Meio Ambiente (CONAMA), Brasília, DF, 2011.

BRITO-PELEGRINI, N. N.; PATERNIANI, J. E. S.; BROTA, G, A.; SANTOS, E, M.; SILVA, N. B.; PELEGRINI, R. T. Ensaios Biológicos com Sementes para Avaliar A Redução Da Toxicidade do Chorume Tratado por Processo Fotoquímico. Minerva, v. 6, n. 3, p. 219-228, 20 ??.

HINZ, B.; CHEREMINA, O.; BACHMAKOV, J.; RENNER, B.; ZOLK, O.; FROMM, M. F.; BRUNE, K. Dipyrone elicits substantial inhibition of peripheral cyclooxygenases in humans: new insights into the pharmacology of an old analgesic, The FASEB Journal, v. 21, p. 1-9, 2007.

LOPES, A. C. A.; NASCIMENTO, W. M. Dormência em sementes de hortaliças. Documentos da EMBRAPA, ISSN: 1415-2312, p. 1-25, 2012.

MALATO, S., BLANCO, J., VIDAL, A., RICHTER, C.; Photocatalysis with Solar Energy at a Pilotplant Scale: an overview, Applied Catalysis B: Environmental, v. 37, p. 1-15, 2002.

MELO, S. A. S.; TROVÓ, A. G.; BAUTITZ, I. R.; NOGUEIRA, R. F. P.; Degradação de fármacos por processos oxidativos avançados. Química Nova, v. 32, n. 1, 2009. 
NAPOLEÃO, D. C.; Avaliação e Tratamento dos Contaminantes Emergentes (Ácido Acetilsalicílico, Diclofenaco e Paracetamol) utilizando Processos Oxidativos Avançados. Dissertação de Mestrado, Recife, PE: UFPE, 2011.

REIS FILHO, R. W.; ARAÚJO, J. C.; VIEIRA, E. M. Hormônios Sexuais estrógenos: Contaminantes Bioativos. Química Nova, v. 29, n. 4, 817-822, 2006.

SCHWARZENBACH, R. P.; ESCHER, B. I.; FENNER, K.; HOFSTETTER, T. B.; JOHNSON, C. A.; VON GUNTEN, U.; WEHRLI, B.; Science, v.1072; p. 313, 2006.

ZAFRA-GÓMEZ, A., BALlESTEROS, O. NAVALÓN, A., VÍLCHEZ, J. L.; Determination of some endocrine disrupter chemicals in urban wastewater samples using liquid chromatography-mass spectrometry, Microchemical Journal, v. 88, p. 87-94, 2008. 